\title{
Self-awareness of HbA1c and its association with glycemic control among patients with type 2 diabetes: A multicenter study
}

Joud Shabeeb Almutairi ( $\nabla$ dr.jouds@hotmail.com )

King Saud Medical City

Turky H Almigbal

King Saud University

Hiba Y Alraheem

King Saud University

Muhammad H Mujammami

King Saud University

Turki A AlMogbel

king fahd specialist hospital

Abdullah M Alshahrani

University of Bisha

Abdullah M Al Zahrani

King Saud bin Abdulaziz University for Health Sciences

Mohammed A Batais

King Saud University

\section{Research}

Keywords: HbA1c, self-awareness, glycemic control, diabetes

Posted Date: July 21 st, 2020

DOI: https://doi.org/10.21203/rs.3.rs-44321/v1

License: (c) (1) This work is licensed under a Creative Commons Attribution 4.0 International License.

Read Full License

Version of Record: A version of this preprint was published at Saudi Medical Journal on March 1st, 2022. See the published version at https://doi.org/10.15537/smj.2022.43.3.20210536. 


\section{Abstract \\ Background}

Diabetes-related complications can be prevented by maintaining good glycemic control. Despite huge efforts to obtain acceptable glycemic control among diabetics, this has not yet been achieved. Thus, there is a need to discover all factors that might affect glycemic control. Here, our main aim was to assess the association between self-awareness of Hemoglobin A1c $(\mathrm{HbA} 1 \mathrm{c})$ among Saudi patients with type 2 diabetes and glycemic control, thereby identifying those factors that might affect the glycemic control.

\section{Methods}

The data for this study was collected using questionnaires through interviews among 600 patients with type 2 diabetes. The study was conducted in outpatient diabetes clinics in tertiary hospitals in Riyadh, Qassim and Jeddah, Saudi Arabia. The data collection was done during the period from March and April 2018. The subject's self-awareness about the HbA1c test was assessed based on the combined score of four questions. The latest $\mathrm{HbA} 1 \mathrm{c}$ result before the time of data collection was obtained from medical records. Frequencies and percentages were calculated for all categorical variables used in the analysis. Means and standard deviations were calculated for continuous variables. A p-value of less than 0.05 was considered statistically significant for all analyses.

\section{Results}

The mean age of the respondents was 54.7 years, and the mean duration of diabetes was 11.9 years. The prevalence of $\mathrm{HbA} 1 \mathrm{c}$ self-awareness was approximately $40 \%$. Overall, $63.9 \%$ accurately reported their Hemoglobin A1C Self-Knowledge (HbA1csk). The prevalence of good glycemic control (defined as HbA1c less than $7.0 \%$ ) was $21.0 \%$. Five of the participants' characteristics were associated with better glycemic control: good HbA1c self-awareness ( $\mathrm{OR}=3.25,95 \% \mathrm{Cl}: 1.15-9.24)$, duration of diabetes (negatively associated with glycemic control) $(\mathrm{OR}=0.91,95 \% \mathrm{Cl}: 0.87-0.95)$, discussed $\mathrm{HbA} 1 \mathrm{c}$ target with the health care provider ( $\mathrm{OR}=2.42,95 \% \mathrm{Cl}: 1.22-4.79)$, monthly income between 10,001 and $15,000 \mathrm{SR}(\mathrm{OR}=2.28$, $95 \% \mathrm{Cl}: 1.13-4.60)$, and number of follow up visit $(\mathrm{OR}=0.77,95 \% \mathrm{Cl}: 0.63-0.94)$.

\section{Conclusions}

We conclude that there is a positive association between $\mathrm{HbA} 1 \mathrm{c}$ self-awareness and glycemic control. Glycemic control was good among those who were educated about the meaning of the test, their levels, and their target goal. Awareness among health care providers regarding the role of the patient's education about their condition might help in providing the patient with optimal care. Further studies with different 
experimental designs are needed to study this association, which will contribute to the development of a structured educational program.

\section{Introduction}

Type 2 diabetes mellitus (DM) is one of the most common chronic non-communicable diseases. DM is characterized by hyperglycemia due to the inadequate production of insulin or the inability of the body's cells to respond to it, known as insulin resistance (1). Its prevalence is increasing globally, which is adding to the burden on healthcare resources. According to the International Diabetes Federation (IDF), the worldwide prevalence of diabetes was 463 million in 2019, and it is expected to rise to reach 578 million adults with diabetes by 2030, and 700 million by 2045 (2). Locally, it is estimated that $23.7 \%$ of Saudi adults have been diagnosed with diabetes (3).

Maintaining good glycaemic control is considered the primary goal of diabetes management (4). Good glycaemic control carries the benefits of improving a patient's life and preventing or delaying its harmful complications (5). These complications include microvascular (nephropathy, neuropathy, retinopathy) and macrovascular (cardiovascular and cerebrovascular disease) complications (6). The HbA1c test is one of the most important biomarkers, and has been approved by the World Health Organization (WHO) for diagnosing diabetes and monitoring glycemic control (7-9). The HbA1c test carries the advantages of being measured at any time, and it does not require fasting. The advantage is that the HbA1c test can be used to reflect the average blood glucose level over the previous 3 months, which makes it the best option for the long-term management of type 2 diabetes (8).

Suboptimal control of HbA1c can lead to the development of harmful acute or chronic complications (10). Suboptimal control of HbA1c increases the risk of developing cardiovascular disease (CVD) by 2- to 3-times, and end-stage renal disease (ESRD) by 10-times when comparing patients with diabetes and those who do not have diabetes. Diabetic peripheral neuropathy can affect from $16-66 \%$ of all people with diabetes, while more than one-third of these can be affected by diabetic retinopathy $(2,11)$. This can be attributed to many reasons, such as that many patients remain undiagnosed for years due to a lack of symptoms. Several studies have shown a high proportion of patients who had poor glycemic control worldwide, despite the huge effort that has been done to control their diabetes and manage their modifiable risk factors (12-15). Although many studies have aimed to evaluate the factors associated with good glycemic control (16), there is a dearth of studies evaluating the unusual factors related to suboptimal control, such as patients' self-awareness of their own glucose level and $\mathrm{HbA} 1 \mathrm{c}$ as a part of self-care behavior.

Although much research has shown a favorable effect of a structured education about HbA1c on glycemic control, there are no Saudi studies addressing the relationship between the extent of selfawareness of $\mathrm{HbA1c}$ and glycemic control. This is an important gap in the local literature that needs to be addressed, especially because Saudi Arabia represents a different culture and healthcare system, and it 
has a high prevalence of diabetes. The main objective of the current study was to assess the association between the self-awareness of $\mathrm{HbA} 1 \mathrm{c}$ and glycemic control.

\section{Methods}

\section{Study design and site}

This study is a cross-sectional survey using an interview questionnaire investigating the prevalence of $\mathrm{HbA1c}$ self-awareness among Saudi patients with type 2 diabetes, the accuracy of reported HbA1c, their association with glycemic control, and the factors that might be related to glycemic control. The study was conducted in the outpatient diabetes clinic at tertiary hospitals in Riyadh, Qassim, and Jeddah.

\section{Eligibility criteria}

The inclusion criteria were: either male or female patients between the ages of 18-75 years, who had been diagnosed with type 2 diabetes mellitus for at least 1 year, and who have regular follow up visits for diabetes care. We excluded any patients younger than 18 years and older than 75 years, those with a past history of bariatric surgery, past history of renal insufficiency, with a creatinine level greater than 1.5 $\mathrm{mg} / \mathrm{dl}$, with known underlying illness (e.g., malignancy or hemoglobinopathies), that received a blood transfusion within the past 30 days, or being pregnant. Also, the participants were excluded if, for any reason, they did not have the ability to communicate verbally.

\section{Patient enrolment}

Patients were approached by using a simple time random interval technique (17). Three different days every week were chosen. During the early morning of each of these days, we visited the outpatient diabetes clinics and obtained the sample frame of all patients who met our inclusion criteria. A random sample was then selected from the sample frame. The informed consent form was taken from the patients before the administration of the questionnaire, and all patient's information was handled with strict confidentiality. Trained data collectors were assigned to collect the data at each center, and all of them followed the same process. The data was collected using the questionnaire through face-to-face interviews from March to April 2018.

\section{Instrument development}

Data for this study were collected using a questionnaire through an interview. The interview questionnaire was developed based on an extensive literature review and experts' opinions (18-21). The questionnaire was composed of two main sections. The first section assessed the patient's background information (age, gender, nationality, highest educational level, location, monthly income, current occupation, marital 
status, smoking status, duration of diabetes, and type of diabetes treatment). The second part addressed $\mathrm{HbA1c}$ (medication compliance, frequency of hospital visits, patient awareness of $\mathrm{HbA1c}$, and education about the test and its target by a healthcare provider). The most recent $\mathrm{HbA1c}$, weight, and height data were gathered by the data collector from the patient's file.

The patient's self-awareness of $\mathrm{HbA} 1 \mathrm{c}$ was assessed based on a score of four questions. Patients were asked if they have heard about or are aware of the term $\mathrm{HbA} 1 \mathrm{c}$. Those who answered yes proceeded to answer three other questions on $\mathrm{HbA} 1 \mathrm{c}$, including what does $\mathrm{HbA} 1 \mathrm{c}$ mean, their target $\mathrm{HbA} 1 \mathrm{c}$ goal, and whether they can correctly identify their current $\mathrm{HbA} 1 \mathrm{c}$ value. Participants were categorized as having good $\mathrm{HbA} 1 \mathrm{c}$ self-awareness if they could answer 3 out of 4 questions on HbA1c correctly. While those who did not hear about the test before or scored less than 3 out of 4 were categorized as not having a good awareness of the test (19). The reported HbA1c was considered accurate if within $\pm 0.5 \%$ of the recorded $\mathrm{HbA} 1 \mathrm{c}$. Glycemic control was defined as having a measure of $\mathrm{HbA} 1 \mathrm{c}$ of less than $7 \%$.

The questionnaire was initially developed in English. Two accredited translators were assigned to translate it to Arabic and then back-translated it to English, both the original and final English versions were reviewed, and any disagreements between them were solved by the principal author and the translators $(22,23)$. To check the validity and reliability of the final Arabic version, a pilot study was done that included 60 patients with type 2 diabetes. The piloted participants were not included in the study.

\section{Sample size calculation}

Using the following single proportion formula, assuming that alpha is equal to 1.96 for a $95 \%$ confidence level, the precision is equal to $4 \%$, and a prevalence of $50 \%$, the calculated sample size was 600 subjects.

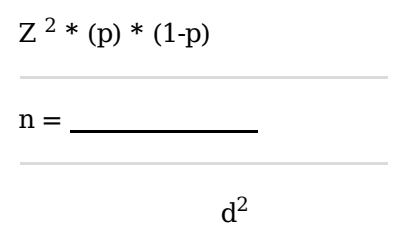

where: $Z=Z$ value, $p=$ the prevalence, and $d=$ precision .

\section{Statistical analyses}

All analyses were conducted using SAS Version 9.3 (SAS Institute, Inc, Cary, NC) $(24,25)$. Frequencies and percentages were calculated for all categorical variables used in the analysis. Means and standard deviations were calculated for continuous variables. A p-value of less than 0.05 was considered statistically significant for all analyses.

Mean self-reported $\mathrm{HbA} 1 \mathrm{c}$ with the corresponding standard deviation was calculated for patients who had reported their HbA1c. Additionally, mean laboratory-generated HbA1c and corresponding standard 
deviations were calculated for all patients. Levene's test was used to examine whether the variance in the mean laboratory-generated $\mathrm{HbA} 1 \mathrm{c}$ values was different between those who had reported their $\mathrm{HbA} 1 \mathrm{c}$ and those who had not. We also calculated the mean difference between these two groups and corresponding $95 \%$ confidence intervals for these mean differences. Finally, a Peta-square was calculated to determine whether these mean values were significantly different. We performed the same analysis comparing mean reported, and actual $\mathrm{HbA} 1 \mathrm{c}$ values among patients who had accurately and inaccurately reported their HbA1c.

An interclass correlation coefficient (ICC) was calculated to determine the relationship between actual and reported $\mathrm{HbA} 1 \mathrm{c}$ among patients who had reported their HbA1c.

T-tests were performed to determine whether the mean values for several continuous variables were different among those who had good HbA1c self-awareness and those who did not. We also used chisquare tests to determine whether the distribution of different categorical variables was different between these two groups. We performed the same comparisons between those who had good self- awareness and knew their HbA1c goal and those who had good self-awareness but did not know their HbA1c goals.

A chi-square test was also performed to determine whether the distribution of different categorical variables was different among those with glycemic control and without glycemic control.

Finally, logistic regression was performed to determine whether the odds of having glycemic control differed significantly according to $\mathrm{HbA1c}$ self-awareness, socio-demographic, and clinical characteristics as covariates. We ran univariate models to examine these characteristics separately, and a multivariate model examining all variables simultaneously.

\section{Results}

\section{Participant's socio-demographic and clinical characteristics}

A total of 600 participants were enrolled in this study. The mean age of the respondents was 54.7 years, and the mean duration of diabetes was 11.9 years. Most (45\%) of the participants were on tablets alone as a treatment for this condition. Among all participants, the mean $\mathrm{HbA1c}$ level was $8.6 \%(S D=1.19)$; while among those who reported knowing their $\mathrm{HbA} 1 \mathrm{c}$, the mean $\mathrm{HbA} 1 \mathrm{c}$ level was $(7.6 \%, \mathrm{SD}=1.3)$, which was very close to the self-reported $\mathrm{HbA} 1 \mathrm{c}$ levels among this population $(7.4 \%, \mathrm{SD}=1.4)$. With respect to knowledge about $\mathrm{HbA} 1 \mathrm{c}$ and control, most participants $(360,60 \%)$ did not have good $\mathrm{HbA} 1 \mathrm{c}$ selfawareness. Only $126(21.0 \%)$ of the participants had HbA1c levels indicative of good glycemic control. The remaining socio-demographic and clinical characteristics are shown in Table 1.

Figure 1 shows the details of the self-awareness of HbA1c among the participants. The majority (74.8\%) of the participants had heard of the $\mathrm{HbA} 1 \mathrm{c}$ test before. Among those respondents who had heard about the test before, $60.2 \%$ were not aware of the meaning of the $\mathrm{HbA} 1 \mathrm{c}$ test, $41.8 \%$ knew their target goal, and $44.8 \%$ were aware of their last $\mathrm{HbA} 1 \mathrm{c}$ result. Also, the majority $(61.8 \%$ and $59.0 \%)$ of the participants were 
not educated by their health care providers about the meaning of the HbA1c test or their HbA1c's target goal, respectively.

\section{Relationship between reported and actual HbA1c}

As shown in Table 2, the mean self-reported $\mathrm{HbA} 1 \mathrm{c}(7.4 \%, \mathrm{SD}=1.4)$ was similar to the actual HbA1c $(7.6 \%, S D=1.3)$ among patients who reported knowing their HbA1c levels. Actual HbA1c levels were also significantly lower among those who reported their HbA1c levels (7.6\%, SD = 1.3) compared to those who had not $(9.4 \%, S D=1.9)$. The mean difference between these two groups was $1.8 \%(95 \% \mathrm{Cl}=1.5,2.0)$. As shown in Table 3 , there was a very high level of agreement $(0.94 ; 95 \% \mathrm{Cl}=0.89,0.99)$ between selfreported $\mathrm{HbA} 1 \mathrm{c}$ and actual HbA1c among patients who self-reported their $\mathrm{HbA1c}$.

Table 4 shows that among patients who accurately reported their $\mathrm{HbA} 1 \mathrm{c}$, there was a small and nonsignificant difference between their actual and reported $\mathrm{HbA} 1 \mathrm{c}$ levels $(-0.1,95 \% \mathrm{Cl}=-0.5,0.2)$. There was a much larger and significant difference between reported and actual HbA1c among patients who inaccurately reported their $\mathrm{HbA} 1 \mathrm{c}$ levels $(0.6,95 \% \mathrm{Cl}=0.2,0.9)$.

\subsection{Comparison of those aware and unaware of HbA1c}

Table 5 shows the comparison of demographic and clinical details between those who had good HbA1c self-awareness (group A) and those who did not (group B). Mean age and duration of diabetes were significantly lower in group A compared to group B. Mean HbA1c was significantly lower in group $A$ (7.5\%) compared to group B (9.3\%) with p-value <0.0001. self-awareness of HbA1c was significantly associated with those who know their HbA1c level or have been educated about HbA1c meaning or target goal by their health care provider. The proportion of subjects with higher education or high monthly income was more in group A compared to B. There was no significant difference in the number of followup visits between the two groups.

\subsection{Glycemic control according to characteristics of study participants}

Table 6 shows the association between glycemic control and the respondents' socio-demographic and clinical characteristics. Glycemic control was significantly associated with good HbA1c self-awareness (70.6\%) compared to (29.4\%) in the unaware group. Also, there was a significant association between good glycemic control and being exposed to the term of HbA1c before (91.3\%), know current $\mathrm{HbA} 1 \mathrm{c}$ value $(71.4 \%)$ or being educated by the health care provider about the meaning of the test or the target goal $(62.7 \%, 69 \%)$ respectively. 
Additionally, good glycemic control was associated with high educational level, high monthly income and being from outside Riyadh. Those with glycemic control were more likely to be on no treatment, diet treatment or tablets only. While those without glycemic control were more likely to be on insulin treatment only or tablets and insulin. There were no significant associations between glycemic control and occupation, nationality, marital status, smoking and medication compliance.

Multivariable logistic regression analysis was used to predict the participants' glycemic control by their socio-demographic and clinical characteristics. After adjusting for the occupation, nationality, marital status, smoking and medication compliance, five participants' characteristics were associated with glycemic control. These characteristics were good HbA1c self-awareness (OR=3.25, 95\% Cl: 1.15-9.24), duration of diabetes was significantly negatively associated with glycemic control (OR=0.91, 95\% Cl: 0.87 0.95), discussed $\mathrm{HbA} 1 \mathrm{c}$ target with the health care provider ( $\mathrm{OR}=2.42,95 \% \mathrm{Cl}: 1.22-4.79)$, monthly income between 10,001 and $15,000 \mathrm{SR}(\mathrm{OR}=2.28,95 \% \mathrm{Cl}: 1.13-4.60)$ and number of follow up visit $(\mathrm{OR}=0.77$, $95 \% \mathrm{Cl}: 0.63-0.94)$. No significant association has been found between the participants' glycemic control and the other socio-demographic and clinical characteristics (Table 7).

\section{Discussion}

The key findings of this multicenter study show that the prevalence of HbA1c self-awareness is approximately $40 \%$. Overall, $63.9 \%$ of those with the self-knowledge of their own $\mathrm{HbA} 1 \mathrm{c}$ level accurately reported their HbA1csk (when compared to their own laboratory value). Furthermore, participants who report an accurate value for HbA1csk have a statistically significant $(p<0.0008)$ lower mean HbA1c Lab (7.4\%) compared to those participants who report an inaccurate value for their own $\mathrm{HbA} 1 \mathrm{c}$ (mean $8.0 \%$ ). The prevalence of glycemic control (defined as HbA1c less than $7.0 \%$ ) was $21.0 \%$. Among those who had good $\mathrm{HbA} 1 \mathrm{c}$ self-awareness, $70.6 \%$ were found to have good glycemic control $(p<0.0001)$. In a multivariate model controlling for several factors thought to impact glycemic control, patients who had high HbA1c self-awareness had over 3-times the odds of having glycemic control compared to other patients.

In a European study, which was conducted in 2017 over eight European countries to evaluate the prevalence of accurate self-knowledge of a patient's own HbA1c level and its association with glycemic control. $49.4 \%$ of the patients reported their $\mathrm{HbA} 1 \mathrm{c}$, and among those patients, $78.3 \%$ accurately reported it(18). While in our study, among the 269

Patients who reported knowing their $\mathrm{HbA} 1 \mathrm{c}$ level, $63.9 \%$ reported it accurately (i.e., reported $\mathrm{HbA} 1 \mathrm{c}$ with $0.5 \%$ of actual measured $\mathrm{HbA} 1 \mathrm{c}$ ). This percentage is substantially lower than that estimated by another study. However, in a study conducted in the United States, only $25 \%$ of patients accurately reported their $\mathrm{HbA1c}$, a lower percentage than that reported in this study(26). Both studies resulted in that poor HbA1c recall was significantly associated with having a higher recorded $\mathrm{HbA1c}$ level, implying poor selfknowledge of one's own HbA1c was associated with worse glycemic control. These two studies deal with 
substantially different sample sizes and populations from each other and from those described in this study.

In our study, the group who had good HbA1c self-awareness was found to have a statistically significantly lower recorded $\mathrm{HbA} 1 \mathrm{c}$ Lab (7.5\%) compared to the unaware group (9.3\%). This fact is consistent with the literature. In studies conducted in India and England, patients with good HbA1c selfawareness were found to have substantially lower $\mathrm{HbA} 1 \mathrm{c}$ levels than other patients(19, 27). Additionally, there was a statistically significant association between having good glycemic control and being educated by health care providers about the meaning, current and target $\mathrm{HbA} 1 \mathrm{c}$ goal. Also, it was associated with younger age, less duration of diabetes, highest educational level, high monthly income and being from outside Riyadh.

The main strength of this study is the first of its kind to assess the unusual factors which may affect glycemic control here in Saudi Arabia, multicenter study, large sample size, randomly chosen participants and data for a wide variety of different covariates was collected for this study. The availability of this data allowed us to assess whether our findings were confounded. Even when controlling for these potential confounders, HbA1c self-awareness remained a significant and substantial predictor of glycemic control.

This study also has some limitations. All data were collected cross-sectionally. Therefore the causal relationship between the dependent and independent variables cannot necessarily be known for certain. For example, this study's primary finding is that there is a strong association between HbA1c selfawareness and glycemic control. Based on these data, we cannot say with certainty that HbA1c selfawareness causes patients to have better glycemic control. A longitudinal study in which data about $\mathrm{HbA1c}$ self-awareness was collected first and changes in $\mathrm{HbA1c}$ were compared among those with and without good self- awareness were compared would be a better way of address causality.

These findings have important public health and clinical significance. Type 2 diabetes remains a growing problem around the world and in Saudi Arabia as well. Several studies showed a high prevalence of poor glycemic control worldwide $(12,15)$. Therefore, unless the unusual factors discovered to promote glycemic control among those with type 2 diabetes, the burden of this problem on the health care system will increase. This study provides valuable prevalence data and can give birth to future prospective randomized controlled studies to examine the effect of HbA1c self-awareness as part of a structured educational program on outcome $\mathrm{HbA} 1 \mathrm{c}$ and suggest that the effort to educate health care providers and patients may have had a beneficial effect.

We conclude that there is a positive association between HbA1c self-awareness and glycemic control. Glycemic control was good among those who were educated about the meaning of the test, their level and their target goal. Awareness among health care providers regarding the role of the patient's education about their condition might help in providing the patient with optimal care. Further studies with different experimental designs are needed to study this association as a part of a structured educational program. 


\section{Declarations}

\subsection{Ethical consideration}

Institutional Review Board (IRB) approval No. (E-18-3084) was obtained before the beginning of this study from each center. Participants were informed about the study's objectives, and their permission to enter the study was requested. Written consent was obtained from the participants. The confidentiality of their information was assured.

\subsection{Consent for publication}

Not applicable

\subsection{Availability of data and materials}

The datasets used and/or analyzed during the current study are available from the corresponding author on reasonable request.

\subsection{Competing interest}

All authors have no competing interests.

\subsection{Funding}

This project was supported by the College of Medicine Research Centre, Deanship of Scientific Research, King Saud University, Riyadh, Saudi Arabia.

\subsection{Authors' contribution}

All authors were involved in the conception and paper design. All authors reviewed the final manuscript and finalized the paper.

\subsection{Acknowledgments}

None.

\section{References}

1. Baynes $\mathrm{H}$. Classification, pathophysiology, diagnosis and management of diabetes mellitus. $\mathrm{J}$ diabetes metab. 2015;6(5):1-9.

2. Saeedi P, Petersohn I, Salpea P, Malanda B, Karuranga S, Unwin N, et al. Global and regional diabetes prevalence estimates for 2019 and projections for 2030 and 2045: Results from the International Diabetes Federation Diabetes Atlas. Diabetes research and clinical practice. 2019;157:107843.

3. Al-Nozha MM, Al-Maatouq MA, Al-Mazrou YY, Al-Harthi SS. Diabetes mellitus in saudi arabia. 2004. 
4. Group UPDS. Intensive blood-glucose control with sulphonylureas or insulin compared with conventional treatment and risk of complications in patients with type 2 diabetes (UKPDS 33). The lancet. 1998;352(9131):837-53.

5. Glasgow RE, Ruggiero L, Eakin EG, Dryfoos J, Chobanian L. Quality of life and associated characteristics in a large national sample of adults with diabetes. Diabetes Care. 1997;20(4):562-7.

6. Stumvoll M, Goldstein BJ, van Haeften TW. Type 2 diabetes: principles of pathogenesis and therapy. The Lancet. 2005;365(9467):1333-46.

7. Consensus statement on the worldwide standardization of the hemoglobin $\mathrm{A} 1 \mathrm{C}$ measurement: the American Diabetes Association. European Association for the Study of Diabetes, International Federation of Clinical Chemistry and Laboratory Medicine, and the International Diabetes Federation. Diabetes Care. 2007;30(9):2399-400.

8. Organization WH. Use of glycated haemoglobin ( $\mathrm{HbA1c}$ ) in diagnosis of diabetes mellitus: abbreviated report of a WHO consultation. 2011.

9. Bonora E, Tuomilehto J. The pros and cons of diagnosing diabetes with A1C. Diabetes Care. 2011;34(Supplement 2):184-S90.

10. Kibirige D, Akabwai GP, Kampiire L, Kiggundu DS, Lumu W. Frequency and predictors of suboptimal glycemic control in an African diabetic population. Int J Gen Med. 2017;10:33.

11. Alzaheb RA, Altemani AH. The prevalence and determinants of poor glycemic control among adults with type 2 diabetes mellitus in Saudi Arabia. Diabetes, metabolic syndrome and obesity: targets and therapy. 2018;11:15.

12. Najafipour H, Sanjari M, Shokoohi M, Haghdoost AA, Afshari M, Shadkam M, et al. Epidemiology of diabetes mellitus, pre-diabetes, undiagnosed and uncontrolled diabetes and its predictors in general population aged 15 to 75 years: A community-based study (KERCADRS) in southeastern Iran. Journal of diabetes. 2015;7(5):613-21.

13. Siddiqui FJ, Avan BI, Mahmud S, Nanan DJ, Jabbar A, Assam PN. Uncontrolled diabetes mellitus: Prevalence and risk factors among people with type 2 diabetes mellitus in an Urban District of Karachi, Pakistan. Diabetes Res Clin Pract. 2015;107(1):148-56.

14. Bi Y, Zhu D, Cheng J, Zhu Y, Xu N, Cui S, et al. The status of glycemic control: a cross-sectional study of outpatients with type 2 diabetes mellitus across primary, secondary, and tertiary hospitals in the Jiangsu province of China. Clinical therapeutics. 2010;32(5):973-83.

15. Ahmad NS, Islahudin F, Paraidathathu T. Factors associated with good glycemic control among patients with type 2 diabetes mellitus. Journal of diabetes investigation. 2014;5(5):563-9.

16. Elfil M, Negida A. Sampling methods in clinical research; an educational review. Emergency. 2017;5(1).

17. Trivedi H, Gray LJ, Seidu S, Davies MJ, Charpentier G, Lindblad U, et al. Self-knowledge of HbA1c in people with Type 2 Diabetes Mellitus and its association with glycaemic control. Primary care diabetes. 2017;11(5):414-20. 
18. Beard E, Clark M, Hurel S, Cooke D. Do people with diabetes understand their clinical marker of longterm glycemic control ( $\mathrm{HbA} 1 \mathrm{c}$ levels) and does this predict diabetes self-care behaviours and $\mathrm{HbA} 1 \mathrm{c}$ ? Patient Educ Couns. 2010;80(2):227-32.

19. Samsudin IN, Thambiah SC, Ayub WMAWM, Cheng NW, Hussein Z, Noor NM, et al. Awareness of Glycosylated Haemoglobin (HbA1c) Among Type 2 Diabetes Mellitus Patients in Hospital Putrajaya. Education.13:14.1.

20. Matheka DM, Kilonzo JM, Munguti CM, Mwangi PW. Pattern, knowledge and practices of HbA $1 \mathrm{C}$ testing among diabetic patients in a Kenyan tertiary referral hospital. Globalization health. 2013;9(1):55.

21. Organization WH, Organization WH. Management of substance abuse: Process of translation and adaptation of instruments. 2017.

22. Inc SI. SAS User's Manual, version 9.3. North Carolina: SAS Institute Inc Cary; 2013.

23. Heisler M, Piette JD, Spencer M, Kieffer E, Vijan S. The relationship between knowledge of recent $\mathrm{HbA} 1 \mathrm{c}$ values and diabetes care understanding and self-management. Diabetes Care. 2005;28(4):816-22.

24. Kumpatla S, Medempudi S, Manoharan D, Viswanathan V. Knowledge and Outcome Measure of HbA1c Testing in Asian Indian Patients with Type 2 Diabetes from a Tertiary Care Center. Indian J Community Med. 2010;35(2):290-3.

\section{Tables}

Table 1: Descriptive statistics for participants in study, $\mathrm{n}=600$. 


\begin{tabular}{|c|c|c|}
\hline Patients' characteristics & & \\
\hline Age. Mean (SD) & $54.7(9.7)$ & \\
\hline Highest education level. N (\%) & $\begin{array}{l}\text { No school attended } \\
\text { Primary school } \\
\text { Secondary school } \\
\text { Tertiary school } \\
\text { University or college } \\
\text { Masters or PhD }\end{array}$ & $\begin{array}{l}222(37.0) \\
99(16.5) \\
71(11.8) \\
93(15.5) \\
99(16.5) \\
16(2.7)\end{array}$ \\
\hline Location of residency. $\mathrm{N}(\%)$ & $\begin{array}{l}\text { Riyadh } \\
\text { Outside Riyadh }\end{array}$ & $\begin{array}{l}175(29.2) \\
425(70.8)\end{array}$ \\
\hline Monthly income (SAR)*. N (\%) & $\begin{array}{l}<5,000 \\
5,000 \text { to } 10,000 \\
10,001 \text { to } 15,000 \\
>15,000\end{array}$ & $\begin{array}{l}212(35.3) \\
210(35.0) \\
118(19.7) \\
60(10.0)\end{array}$ \\
\hline Current occupation. N (\%) & $\begin{array}{l}\text { Unemployed } \\
\text { Government work } \\
\text { Private company } \\
\text { Retired }\end{array}$ & $\begin{array}{l}372(62.0) \\
121(20.2) \\
10(1.7) \\
97(16.2)\end{array}$ \\
\hline Smoking status. N (\%) & $\begin{array}{l}\text { Never smoked } \\
\text { Former smoker } \\
\text { Current smoker }\end{array}$ & $\begin{array}{l}510(85.0) \\
51(8.5) \\
39(6.5)\end{array}$ \\
\hline Duration of diabetes (years).Mean (SD) & $11.9(8.3)$ & \\
\hline Type of treatment. $\mathrm{N}(\%)$ & $\begin{array}{l}\text { No treatment } \\
\text { Diet only } \\
\text { Tablets only } \\
\text { Insulin only } \\
\text { Tablets and insulin }\end{array}$ & $\begin{array}{l}6(1.0) \\
21(3.5) \\
270(45.0) \\
86(14.3) \\
217(36.2)\end{array}$ \\
\hline Anti-diabetic medications adherence. N (\%) & $\begin{array}{l}\text { No } \\
\text { Yes }\end{array}$ & $\begin{array}{l}49(8.2) \\
550(91.7)\end{array}$ \\
\hline
\end{tabular}




\begin{tabular}{|c|c|c|}
\hline & NA & $1(0.2)$ \\
\hline Heard about HbA1C before. $\mathbf{N}(\%)$ & $\begin{array}{l}\text { No } \\
\text { Yes }\end{array}$ & $\begin{array}{l}151(25.2) \\
449(74.8)\end{array}$ \\
\hline Meaning of HbA1c. N (\%) & $\begin{array}{l}\text {-I do not know } \\
\text {-Reflect the glucose level in the blood over the preceding 2-3 months. } \\
\text {-Reflect the fasting glucose level. } \\
\text {-Other. } \\
\text {-Reflect the glucose level in the blood over the preceding 2-3 weeks. }\end{array}$ & $\begin{array}{l}361(60.2) \\
228(38.0) \\
6(1.0) \\
4(0.7) \\
1(0.2)\end{array}$ \\
\hline Knowing his HbA1c target goal. $\mathrm{N}(\%)$ & $\begin{array}{l}\text { No } \\
\text { Yes }\end{array}$ & $\begin{array}{l}349(58.2) \\
251(41.8)\end{array}$ \\
\hline Knowing his current HbA1c.N (\%) & $\begin{array}{l}\text { No } \\
\text { Yes } \\
\text { NA }\end{array}$ & $\begin{array}{l}329(54.8) \\
269(44.8) \\
2(0.3)\end{array}$ \\
\hline Educated about the meaning of HbA1c by HCP**. N (\%) & $\begin{array}{l}\text { No } \\
\text { Yes }\end{array}$ & $\begin{array}{l}371(61.8) \\
229(38.2)\end{array}$ \\
\hline Educated about HbA1c target by HCP**. N (\%) & $\begin{array}{l}\text { No } \\
\text { Yes }\end{array}$ & $\begin{array}{l}354(59.0) \\
246(41.0)\end{array}$ \\
\hline HBA1C self-awareness. $\mathbf{N}(\%)$ & $\begin{array}{l}\text { Not good } \\
\text { Good }\end{array}$ & $\begin{array}{l}360(60.0) \\
240(40.0)\end{array}$ \\
\hline Glycemic control (Measured HBA1C <7.0). N (\%) & $\begin{array}{l}\text { No } \\
\text { Yes }\end{array}$ & $\begin{array}{l}474(79.0) \\
126(21.0)\end{array}$ \\
\hline Overall actual HBA1C.Mean (SD) & $8.6(1.9)$ & \\
\hline
\end{tabular}


*Saudi Arabia Riyal.

**Health Care Provider.

Table 2: Comparison of mean HbA1cSK* and mean HbA1cLAB** between the participants who reported HbA1cSK and those who did not.

\begin{tabular}{|c|c|c|c|c|c|c|}
\hline & $\begin{array}{l}\text { Reported } \\
\text { HbA1cSK } \\
\text { [269] }\end{array}$ & $\begin{array}{l}\text { Had not } \\
\text { reported } \\
\text { HbA1cSK [331] }\end{array}$ & $\begin{array}{l}\text { Levene's test for } \\
\text { equality of variance } \\
\text { F- statistic } \\
\text { (p-value) }\end{array}$ & $\begin{array}{l}\text { t- } \\
\text { test } \\
\text { (df) }\end{array}$ & $\begin{array}{l}\text { Mean difference } \\
\text { between the two } \\
\text { groups P ( } 95 \% \\
\text { confidence intervals) }\end{array}$ & $\begin{array}{l}\text { Eta- } \\
\text { squared } \\
\text { (eta 2) }\end{array}$ \\
\hline $\begin{array}{l}\text { Mean } \\
\text { HbA1cSK in } \\
\% \text { (SD) }\end{array}$ & $7.4(1.4)$ & $\begin{array}{c}\text { Not } \\
\text { applicaple. }\end{array}$ & Not applicaple. & $\begin{array}{c}\text { Not } \\
\text { applicaple. }\end{array}$ & Not applicaple. & $\begin{array}{l}\text { Not } \\
\text { applicaple }\end{array}$ \\
\hline $\begin{array}{l}\text { Mean } \\
\text { recorded } \\
\text { HbA1cLAB in } \\
\%(\mathrm{SD})\end{array}$ & $7.6(1.3)$ & $9.4(1.9)$ & $\begin{array}{l}23.9 \\
(<0.0001)\end{array}$ & 598 & $1.8(1.5,2.0)$ & $\begin{array}{l}\text { p-value } \\
= \\
<0.0001 \\
\text { eta } 2= \\
0.2177\end{array}$ \\
\hline
\end{tabular}

*HbA1c Self-Knowledge.

**HbA1c lab result.

Table 3: Results of the level of agreement between the grouped variables of reported HbA1cSK* and recorded HbA1cLAB**. 


\begin{tabular}{|l|l|l|l|l|l|}
\hline & Number of Participants & $\begin{array}{l}\text { Level of agreement } \\
\text { statistic }\end{array}$ & $\begin{array}{l}95 \% \\
\text { confidence intervals }\end{array}$ & Degrees of freedom & p \\
\hline ICC & 269 & 0.94 & $0.89,0.99$ & 267 & $<0.0001$ \\
\hline Kappa & 269 & 0.17 & $0.13,0.22$ & 267 & $<0.0001$ \\
\hline
\end{tabular}

*HbA1c Self-Knowledge.

**HbA1c lab result.

Table 4: A comparison of the participants with accurately reported HbA1cSK* and inaccurately reported

HbA1cSK.

\begin{tabular}{|c|c|c|c|c|c|}
\hline & $\begin{array}{l}\text { Accurately } \\
\text { reported HbA1cSK } \\
\text { [172] }\end{array}$ & $\begin{array}{l}\text { Inaccurately } \\
\text { reported HbA1cSK } \\
\text { [97] }\end{array}$ & $\begin{array}{l}\text { Analysis: } t- \\
\text { test/chi- } \\
\text { squared with } \\
\text { degrees of freedom } \\
\text { (df) }\end{array}$ & $\begin{array}{l}\text { Mean difference and 95\% } \\
\text { confidence intervals (CI) } \\
\text { Eta squared (eta 2) }\end{array}$ & $\begin{array}{l}\text { P } \\
\text { Eta 2/phi }\end{array}$ \\
\hline $\begin{array}{l}\text { Mean self- knowledge } \\
\text { HbA1c in \% (SD) }\end{array}$ & $7.4(1.3)$ & $7.3(1.6)$ & 267 & $-0.1(-0.5,0.2)$ & $\begin{array}{l}\mathrm{p}- \\
\text { value } \\
= \\
0.5135 \\
\text { eta } 2= \\
0.0016\end{array}$ \\
\hline $\begin{array}{l}\text { Mean recorded } \\
\text { HbA1c in \% (SD) }\end{array}$ & $7.4(1.2)$ & $8.0(1.4)$ & 267 & $0.6(0.2,0.9)$ & $\begin{array}{l}\mathrm{p}- \\
\text { value } \\
= \\
0.0008 \\
\text { eta } 2= \\
0.0411\end{array}$ \\
\hline
\end{tabular}


*HbA1c Self-Knowledge.

Table 5: Comparison of demographic and clinical details between Group A* and Group B** subjects. 


\begin{tabular}{|c|c|c|c|}
\hline $\mathrm{N}, \mathrm{M}: \mathrm{F}$ & $240,88: 152$ & $360,99: 261$ & \\
\hline \multicolumn{4}{|l|}{ Values are mean $\pm \mathrm{SD}:$} \\
\hline Age (years) & $53.2(10.1)$ & $55.7(9.3)$ & 0.0020 \\
\hline Duration of diabetes (years) & $11.1(8.3)$ & $12.5(11.6)$ & 0.0481 \\
\hline Number of Follow up visits & $2.7(1.3)$ & $2.7(1.5)$ & 0.6716 \\
\hline Mean HbA1c (\%) & $7.5(1.3)$ & $9.3(1.9)$ & $<0.0001$ \\
\hline \multicolumn{4}{|l|}{ No school attended. Primary school. } \\
\hline Secondary school. & $70(31.5)$ & $152(68.5)$ & $<0.0001$ \\
\hline Tertiary school. & $27(27.3)$ & $72(72.7)$ & $<0.0001$ \\
\hline \multicolumn{4}{|l|}{ University or college. Master or $\mathrm{PhD}$. } \\
\hline & $23(32.4)$ & $48(67.6)$ & 0.0030 \\
\hline & $13(81.3)$ & $3(18.8)$ & 0.0124 \\
\hline \multicolumn{4}{|l|}{ Location: Riyadh. OutsideRiyadh. } \\
\hline & $73(41.7)$ & $102(58.3)$ & 0.0284 \\
\hline & $167(39.3)$ & $258(60.7)$ & $<0.0001$ \\
\hline \multicolumn{4}{|l|}{ Monthly income (SAR): } \\
\hline$<5000$ & $59(27.8)$ & $153(72.2)$ & $<0.0001$ \\
\hline $5000-10000$. & $78(37.1)$ & $132(62.9)$ & 0.0002 \\
\hline $10001-15000$ & $64(54.2)$ & $54(45.8)$ & 0.3573 \\
\hline$>15000$ & $39(65.0)$ & $21(35.0)$ & 0.0201 \\
\hline \multicolumn{4}{|l|}{ Current Occupation: Unemployed. } \\
\hline
\end{tabular}

Page 18/24 


\begin{tabular}{|c|c|c|c|}
\hline & $37(38.1)$ & $60(61.9)$ & 0.0195 \\
\hline \multicolumn{4}{|l|}{ Treatment: } \\
\hline No treatment used. Diet only. & $3(50.0)$ & $3(50.0)$ & 1.0000 \\
\hline Tablets only. & $12(57.1)$ & $9(42.9)$ & 0.5127 \\
\hline Insulin only. & $118(43.7)$ & $152(56.3)$ & 0.0385 \\
\hline \multirow[t]{2}{*}{ Tablets andinsulin. } & $30(34.9)$ & $56(65.1)$ & 0.0051 \\
\hline & $77(35.5)$ & $140(64.5)$ & $<0.0001$ \\
\hline \multicolumn{4}{|l|}{ Medication adherence: } \\
\hline \multicolumn{4}{|l|}{ Yes. } \\
\hline \multirow[t]{2}{*}{ No. } & $221(40.1)$ & $330(59.9)$ & $<0.0001$ \\
\hline & $19(38.8)$ & $30(61.2)$ & 0.1161 \\
\hline \multicolumn{4}{|c|}{ Educated about the meaning of HbA1c by HCP: } \\
\hline \multicolumn{4}{|l|}{ Yes. } \\
\hline \multicolumn{4}{|l|}{ No. } \\
\hline & $207(90.4)$ & $22(9.6)$ & $<0.0001$ \\
\hline & $33(8.9)$ & $338(91.1)$ & $<0.0001$ \\
\hline \multicolumn{4}{|c|}{ Educated about the target of HbA1c by HCP: } \\
\hline \multicolumn{4}{|l|}{ Yes. } \\
\hline \multirow[t]{2}{*}{ No. } & $220(89.4)$ & $26(10.6)$ & $<0.0001$ \\
\hline & $20(5.7)$ & $334(94.4)$ & $<0.0001$ \\
\hline \multicolumn{4}{|l|}{ Knowing current HbA1c value: } \\
\hline \multicolumn{4}{|l|}{ Yes. } \\
\hline \multicolumn{4}{|l|}{ No. } \\
\hline & $216(80.3)$ & $53(19.7)$ & $<0.0001$ \\
\hline & $24(7.3)$ & 307 (92.8) & $<0.0001$ \\
\hline
\end{tabular}

* Group A: Aware Group.

**Group B: Unaware group. 
Table 6: Glycemic control according to characteristics of study participants.

Page $20 / 24$ 


\begin{tabular}{|c|c|c|c|c|c|}
\hline Glycemic control & & & & Total n (\%) & \\
\hline Patient characteristic & & No n (\%) & Yes n $(\%)$ & & $P$ value \\
\hline \multirow[t]{3}{*}{ Self-awareness } & Good & $151(31.9)$ & $89(70.6)$ & $240(40.0)$ & $<0.001$ \\
\hline & Not good & $323(68.1)$ & $37(29.4)$ & $360(60.0)$ & \\
\hline & Total & $474(100.0)$ & $126(100.0)$ & $600(100.0)$ & \\
\hline \multirow[t]{3}{*}{ Knowing current HbA1c value: } & Yes. & $179(37.8)$ & $90(71.4)$ & $269(44.8)$ & $<0.0001$ \\
\hline & No. & $295(62.2)$ & $36(28.6)$ & $331(55.2)$ & \\
\hline & Total & $474(100.0)$ & $126(100.0)$ & $600(100.0)$ & \\
\hline \multirow[t]{7}{*}{ Highest Education level: } & No school attended. & $171(36.1)$ & $51(40.5)$ & $222(37.0)$ & 0.0300 \\
\hline & Primary school & $85(17.9)$ & $14(11.1)$ & 99 (16.5) & \\
\hline & Secondary school & $62(13.1)$ & $9(7.1)$ & $71(11.8)$ & \\
\hline & Tertiary school & $73(15.4)$ & $20(15.9)$ & 93 (15.5) & \\
\hline & University or college & $74(15.6)$ & $25(19.8)$ & 99 (16.5) & \\
\hline & Master or $\mathrm{PhD}$. & $9(1.9)$ & $7(5.6)$ & $16(2.7)$ & \\
\hline & Total & $474(100.0)$ & $126(100.0)$ & $600(100.0)$ & \\
\hline \multirow[t]{3}{*}{ Location } & Riyadh. & $150(31.6)$ & $25(19.8)$ & $175(29.2)$ & 0.0096 \\
\hline & Outside Riyadh. & $324(68.4)$ & $101(80.2)$ & $425(70.8)$ & \\
\hline & Total & $474(100.0)$ & $126(100.0)$ & $600(100.0)$ & \\
\hline \multirow[t]{5}{*}{ Monthly income (SAR): } & $<5000$ & $178(37.6)$ & $34(27.0)$ & $212(35.3)$ & $<0.0001$ \\
\hline & $5000-10000$ & $180(38.0)$ & $30(23.8)$ & $210(35.0)$ & \\
\hline & $10001-15000$. & $78(16.5)$ & $40(31.7)$ & 118 (19.7) & \\
\hline & $>15000$ & $38(8.0)$ & $22(17.5)$ & $60(10.7)$ & \\
\hline & Total & $474(100.0)$ & $126(100.0)$ & $600(100.0)$ & \\
\hline \multirow[t]{4}{*}{ Treatment: } & No treatment used. & $3(0.6)$ & $3(2.4)$ & $6(1.0)$ & $<0.0001$ \\
\hline & Diet only. & $11(2.3)$ & $10(7.9)$ & $21(3.5)$ & \\
\hline & Tablets only. & $180(38.0)$ & $90(71.4)$ & $270(45.0)$ & \\
\hline & Insulin only. & $77(16.2)$ & $9(7.1)$ & $86(14.3)$ & \\
\hline
\end{tabular}




\begin{tabular}{|c|c|c|c|c|c|c|}
\hline & \multicolumn{2}{|c|}{ Tablets and insulin. } & $203(42.8)$ & $14(11.1)$ & \multicolumn{2}{|l|}{$217(36.2)$} \\
\hline & \multicolumn{2}{|l|}{ Total } & $474(100.0)$ & $126(100.0)$ & \multicolumn{2}{|l|}{$600(100.0)$} \\
\hline \multirow[t]{3}{*}{ Educated about the meaning of HbA1c by HCP: } & \multicolumn{2}{|l|}{ Yes. } & $150(31.6)$ & $79(62.7)$ & $371(61.8)$ & $<0.0001$ \\
\hline & \multicolumn{2}{|l|}{ No. } & $324(68.4)$ & $47(37.3)$ & \multicolumn{2}{|l|}{$229(38.2)$} \\
\hline & \multicolumn{2}{|l|}{ Total } & 474 (100.0) & 126 (100.0) & \multicolumn{2}{|l|}{$600(100.0)$} \\
\hline \multirow[t]{3}{*}{ Educated about the target of HbA1c by HCP: } & \multicolumn{2}{|l|}{ Yes. } & 159 (33.5) & $87(69.0)$ & $246(41.0)$ & $<0.0001$ \\
\hline & \multicolumn{2}{|l|}{ No. } & $315(66.5)$ & $39(31.0)$ & \multicolumn{2}{|l|}{$354(59.0)$} \\
\hline & \multicolumn{2}{|l|}{ Total } & $474(100.0)$ & $126(100.0)$ & \multicolumn{2}{|l|}{$600(100.0)$} \\
\hline Heard about HbA1C before: & \multicolumn{2}{|l|}{ Yes. } & 334 (70.5) & $115(91.3)$ & 449 (74.8) & $<0.0001$ \\
\hline No. & & 140 (29.5) & & $11(8.7)$ & \multicolumn{2}{|c|}{$151(25.2)$} \\
\hline Total & \multicolumn{3}{|c|}{$474(100.0)$} & $126(100.0)$ & \multicolumn{2}{|c|}{$600(100.0)$} \\
\hline
\end{tabular}

Table 7: Glycemic control according to characteristics of the study population. 


\begin{tabular}{|c|c|c|c|c|c|c|c|}
\hline \multirow[b]{2}{*}{ Patient characteristic } & \multicolumn{3}{|c|}{ Univariate } & \multicolumn{4}{|c|}{ Multivariate } \\
\hline & p-value & OR & $95 \% \mathrm{CI}$ & p-value & & OR & $95 \% \mathrm{CI}$ \\
\hline \multicolumn{8}{|l|}{ Self-awareness } \\
\hline Not good (ref) & - & & & & & & \\
\hline Good & $<0.001$ & 5.40 & $3.50-8.32$ & 0.113 & & 2.57 & $0.80-8.24$ \\
\hline$>60$ & 0.096 & 0.67 & $0.42-1.07$ & 0.693 & & 1.15 & $0.58-2.29$ \\
\hline \multicolumn{8}{|l|}{ Duration of diabetes } \\
\hline$<=10$ years (ref) & - & & & - & & & \\
\hline$>10$ years & $<0.001$ & 0.15 & $0.09-0.26$ & $<0.001$ & & 0.20 & $0.10-0.38$ \\
\hline \multicolumn{8}{|c|}{ Number of follow-up visits } \\
\hline$<=3$ (ref) & - & & & - & & & \\
\hline$>3$ & 0.008 & 0.51 & $0.31-0.84$ & 0.006 & & 0.41 & $0.21-0.77$ \\
\hline \multicolumn{8}{|l|}{ Monthly income } \\
\hline$<5000$ SR (ref) & - & - & - & - & & - & - \\
\hline 5000-10000 SR. & 0.616 & 0.87 & $0.51-1.49$ & 0.997 & & 1.00 & $0.49-2.04$ \\
\hline 10001-15000 SR. & $<0.001$ & 2.68 & $1.58-4.56$ & 0.005 & & 2.92 & $1.39-6.15$ \\
\hline$>15000$ SR & 0.001 & 3.03 & $1.60-5.75$ & 0.237 & & 1.77 & $0.69-4.54$ \\
\hline \multicolumn{8}{|c|}{ Educated about the meaning of HbA1c by HCP: } \\
\hline No (ref) & - & - & - & - & - & & - \\
\hline Yes & $<0.001$ & 3.63 & $2.41-5.47$ & 0.698 & 0.85 & & $0.38-1.93$ \\
\hline \multicolumn{8}{|c|}{ Educated about the target of HbA1c by HCP: } \\
\hline No (ref) & - & & & & & & \\
\hline Yes & $<0.001$ & 4.42 & $2.89-6.75$ & 0.209 & 1.72 & & $0.74-4.03$ \\
\hline
\end{tabular}

\section{Figures}




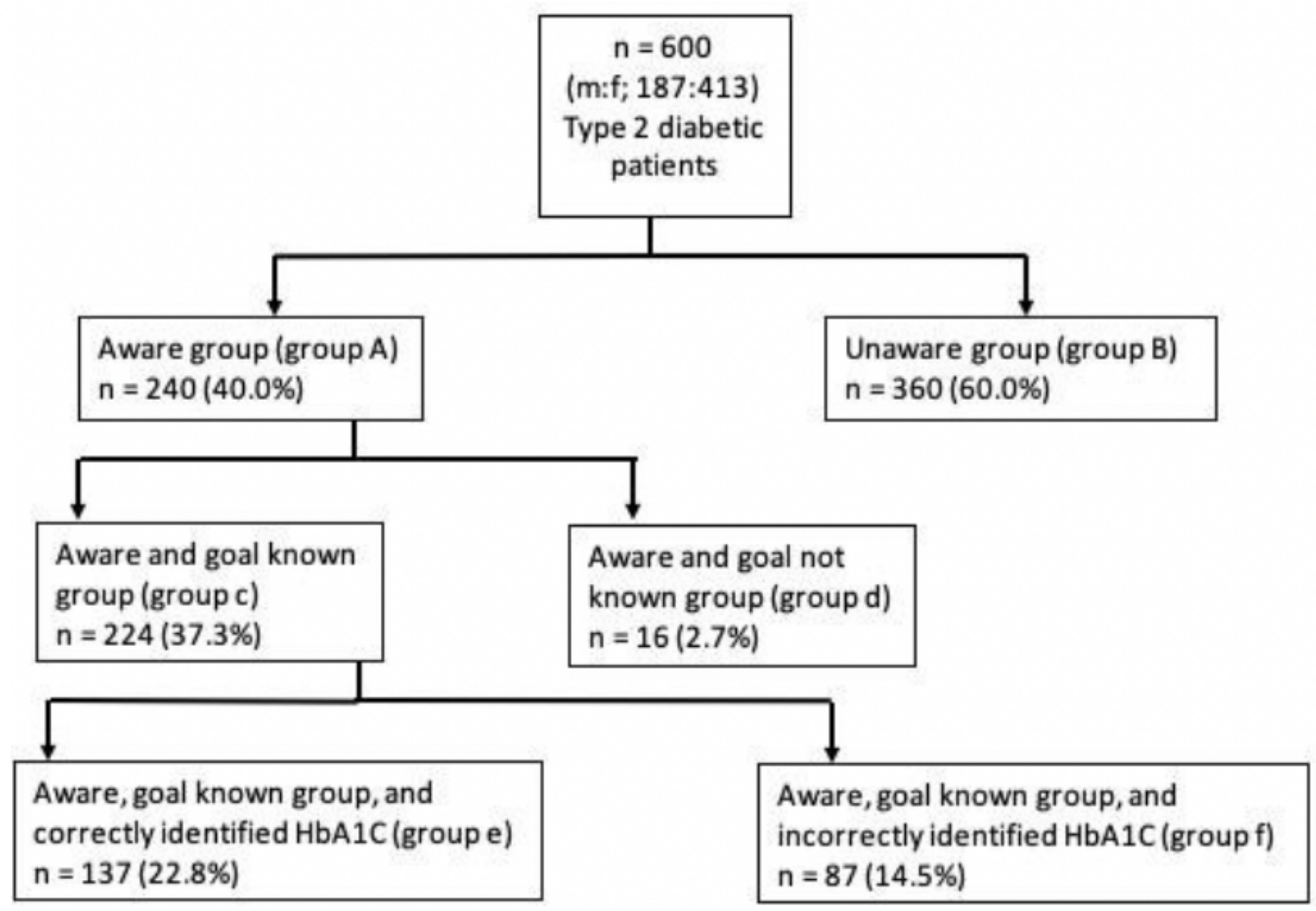

Figure 1

The details of self-awareness of HbA1c among study subjects 